\title{
DNA methylation profiles in ovarian cancer: Implication in diagnosis and therapy (Review)
}

\author{
OURANIA KOUKOURA ${ }^{1}$, DEMETRIOS A. SPANDIDOS ${ }^{2}$, \\ ALEXANDROS DAPONTE $^{1}$ and STAVROS SIFAKIS ${ }^{3}$ \\ ${ }^{1}$ Department of Obstetrics and Gynecology, University Hospital of Larissa, Larissa, Thessaly; \\ ${ }^{2}$ Laboratory of Clinical Virology, University of Crete Medical School; ${ }^{3}$ Department of Obstetrics \\ and Gynecology, University Hospital of Heraklion, Heraklion, Crete, Greece
}

Received April 7, 2014; Accepted May 9, 2014

DOI: $10.3892 / \mathrm{mmr} .2014 .2221$

\begin{abstract}
Genetic alterations alone cannot account for the complexity of ovarian cancer. The potential reversibility of epigenetic mechanisms makes them attractive candidates for the prevention and/or treatment of ovarian carcinoma. Detection of the epigenetic signature of each cancer cell may be useful in the identification of candidate biomarkers for disease detection, classification and monitoring and may also facilitate personalized cancer treatment. In ovarian cancer, in addition to other non-gynaecological cancers, two opposite epigenetic phenomena occur. The first involves an overall global decrease in DNA methylation of heterochromatin leading to demethylation of several oncogenes, while the second involves specific $\mathrm{CpG}$ island hypermethylation associated with the promoters of tumor suppressor genes. Early studies focused on the methylation patterns of single genes associated with tumorigenesis. However, newer genome-wide methods have identified a group of genes whose regulation is altered by DNA methylation during ovarian cancer progression.
\end{abstract}

\section{Contents}

1. Introduction

2. DNA methylation in ovarian cancer

3. Diagnosis

4. Treatment

5. Conclusion

Correspondence to: Dr Ourania Koukoura, Department of Obstetrics and Gynecology, University Hospital of Larissa, P.O. Box 1425, Mezourlo, Larissa 41110, Thessaly, Greece

E-mail: okoukoura@yahoo.com

Key words: biomarkers, DNA methylation, epigenetic mechanisms, oncogenes, ovarian cancer, tumor suppressor genes

\section{Introduction}

Ovarian cancer is the leading cause of gynecologic cancer death, while constituting only $3 \%$ of all female cancers (1). Although the exact cause of ovarian malignancies remains unknown, the fact that $>50 \%$ of deaths occur in postmenopausal women aged 55-74 years, suggests a hormonal risk. Due to the lack of specific symptoms in early stage, $70 \%$ of cases are not diagnosed until the cancer has reached an advanced stage, FIGO Stages IIB to IV (spread of tumor within the pelvis or elsewhere in the abdomen) (2). Early detection of ovarian cancer reportedly increases the five-year survival rate by up to $92 \%$; however, the actual overall five-year survival rate is only $15-45 \%$ (3). Despite advances in cancer research and treatment, these survival statistics have remained largely unchanged for many years. The lack of early detection markers and the development of drug resistance following chemotherapy, are the main obstacles to effective treatment strategies. A better understanding of the molecular pathogenesis of ovarian cancer is needed in order to develop new drug therapies or diagnostic biomarkers and elucidate the role of environmental exposures to the individual's predisposition to the disease.

Ovarian epithelial carcinoma (OEC) is the most common ovarian malignancy, with substantial histopathological heterogeneity. According to the 2003 World Health Organization classification scheme, the most common histologic subtype is serous ovarian carcinoma $(\sim 60 \%)$, while other subtypes include endometrioid (10-20\%), clear cell (10\%), transitional $(6 \%)$, mucinous $(<5 \%)$, and undifferentiated $(<1 \%)$ subtypes $(4)$. The underlying genetic basis of ovarian cancer contributes to this heterogeneity. The majority of OECs (90\%) are sporadic, with the remaining OECs being inherited. Inherited ovarian cancers account for 5-10\% of all ovarian cancers and are characterized by the development of highly aggressive neoplasms at an earlier age of onset than their sporadic counterparts (4). Mutations of BRCA1 and BRCA2 tumor suppressor genes are responsible for most hereditary ovarian cancers. The two genes are essential for DNA repair and play integral roles in genomic stability and integrity (5).

A number of studies (6-8) have reported the use of the candidate gene approach in the search for common risk variants associated with ovarian cancer. Identification of common 
genetic susceptibility alleles may lead to a greater understanding of disease etiology, potentially leading to genetic screening approach that could be used to identify the proportion of the population that would benefit from screening. Genes have been selected from relevant biological pathways, steroid hormone metabolism, DNA repair, apoptosis and cell cycle control, as well as known oncogenes and tumor suppressor genes. However, the genes that participate in the development of ovarian cancer represent only a small portion of the ovarian cancer-associated genes, as many of them are merely associated with ovarian cancer development but do not contribute to its initiation and progression. Moreover, molecular pathways in different ovarian tumors may vary significantly. Thus, genetic alterations alone cannot account for the complexity of ovarian cancer. Since genetic factors are almost impossible to reverse, the potential reversibility of epigenetic mechanisms makes them attractive candidates for the prevention and/or treatment of ovarian carcinoma (9-11).

Epigenetic mechanisms are heritable changes in gene expression without altering the primary DNA sequence (12). Epigenetics involves the interplay between DNA methylation, histone modifications and expression of non-coding RNAs in the regulation of gene transcription (13). Increasing evidence has shown that epigenetic alterations including DNA methylation play a significant role in cancer, from the silencing of tumor suppressors to the activation of oncogenes and the promotion of metastasis (14). DNA methylation is a key element in tissue differentiation during early embryonic development. The diversion of a normal cell cycle to those of a less differentiated status comprises one of the initial steps of tumorigenesis (15). Aberrant DNA methylation is now recognized as one of the most common molecular abnormalities in cancer frequently associated with drug resistance (14).

DNA methylation comprises the best known epigenetic mechanism associated with gene expression. DNA methylation occurs on the cytosine residues of CG (also designated as $\mathrm{CpG}$ ) dinucleotides. Enzymes known as DNA methyltransferases (DNMTs) catalyse the addition of a methyl group to the cytosine ring to form methyl cytosine, employing S-adenosylmethionine as a methyl donor (16). In humans and other mammals, DNA modification occurs predominantly on cytosines that precede a guanosine in the DNA sequence (16). These dinucleotides can be clustered in small stretches of DNA, termed CpG islands, which are often associated with promoter regions. Most $\mathrm{CpG}$ sites outside the $\mathrm{CpG}$ islands are methylated, suggesting a role in the global maintenance of the genome, while most $\mathrm{CpG}$ islands in gene promoters are unmethylated, which allows active gene transcription $(16,17)$. Generally, when a given stretch of cytosines in a $\mathrm{CpG}$ island located in the promoter region of a gene is methylated, that gene is silenced by methylation, and such a $\mathrm{CpG}$ island would be termed 'hypermethylated'. Conversely, when a given stretch of cytosines in a $\mathrm{CpG}$ island located in the promoter region of a gene is not methylated, that gene is not silenced by methylation, and the $\mathrm{CpG}$ island in this case would be 'hypomethylated' (18). Methylation of promoters inhibits their recognition by transcription factors and RNA polymerase, as methylated cytosines preferentially bind to a protein known as methyl cytosine binding protein, or MeCP. When a promoter region normally recognized by an activating transcription factor, is methylated, its transcription is inhibited (19).

The DNA methylation profile of a tumor cell is a reflection of its somatic lineage, environmental exposure and genetic predisposition. The DNA methylation profile is therefore distinct for each histological subtype, suggesting different tumorigenic mechanisms. The detection of the epigenetic signature of each cancer cell may be useful in the identification of candidate biomarkers for disease detection, classification and monitoring and facilitate personalized cancer treatment.

\section{DNA methylation in ovarian cancer}

In ovarian cancer, in addition to other non-gynaecological cancers, two opposite epigenetic phenomena occur: i) An overall global decrease in DNA methylation of heterochromatin leading to demethylation of several oncogenes, ii) specific $\mathrm{CpG}$ island hypermethylation associated with the promoters of tumor suppressor genes $(9,20-22)$ (Fig. 1). The aberrant methylation of $\mathrm{CpG}$ islands in gene promoters has been correlated with a loss of gene expression, and it appears that DNA methylation provides an alternative pathway to gene deletion or mutation for the loss of tumor suppressor gene (TSG) function (23). The epigenetic silencing of TSG induces such mechanisms as uncontrolled cell division, the ability to infiltrate surrounding tissues, metastasis, avoiding apoptosis or sustaining angiogenesis, all of which are responsible for promoting tumor development. In ovarian cancer, a large number of TSGs have been found to undergo hypermethylation (24-26).

One of the most studied genes in ovarian cancer is breast cancer early onset gene 1 (BRCAl) gene, due to its role in inherited and sporadic forms of the disease $(27,28) . B R C A l$ is important in maintaining genomic stability (29), and interacts with numerous proteins, forming complexes that are involved in recognizing and subsequently repairing DNA. Evidence suggests that in cases of sporadic ovarian cancer promoter hypermethylation, non-somatic mutation is the cause for BRCAl inactivation (30). Aberrant methylation of the gene promoter may also serve as an alternative explanation for the loss of heterozygosity associated with BRCAl deficiency in ovarian carcinomas (31). Complete or partial inactivation of the BRCA1 gene through hypermethylation of its promoter has been reported in $15 \%$ of sporadic ovarian tumors $(27,32)$. Hypermethylation leads to the silencing of this gene in ovarian tumors and levels of methylation correlated with decreased $B R C A 1$ expression $(33,34)$. Compared to stage I and healthy subjects, there were higher $B R C A 1$ promoter methylation frequencies in stage II and III ovarian cancers (34). In a series comparing the methylation status of $B R C A l$ among tumor samples obtained from patients with benign ovarian tumors, borderline tumors as well as carcinomas, promoter methylation was detected in $31 \%$ of carcinomas but in none of the benign or borderline tumors (35). Hypermethylation of $B R C A 1$ was detected at a significantly higher frequency in serous carcinomas than in tumors of the other histological types (36). Of note, methylation of $B R C A 1$, while frequent in sporadic ovarian cancer, it has not been reported in the hereditary type of the disease, nor in samples from women with a germ-line BRCA1 mutation $(37,38)$. BRCA2 does not exhibit a similar methylation profile in ovarian cancer (39). 


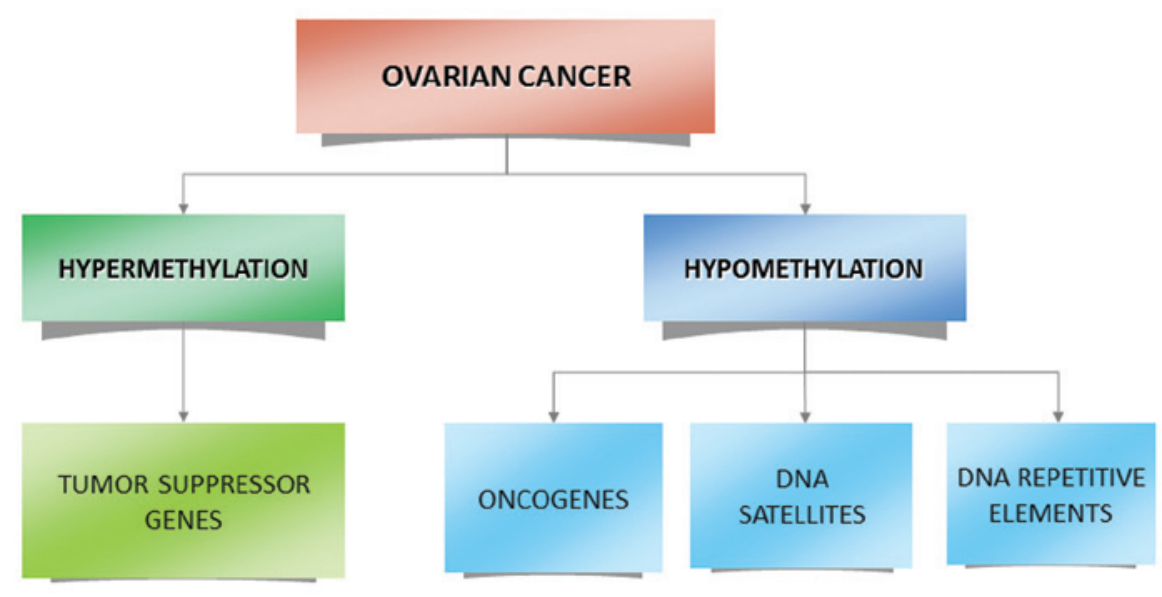

Figure 1. Schematic representation of the methylation events associated with ovarian tumorigenesis.

Findings of previous studies have shown that methylated CpGs at the BRCA2 promoter were either absent or at very low levels in tumor DNA compared to normal tissues (33).

A number of other classical TSGs have been found to undergo hypermethylation in cases of ovarian cancer. Tumor suppressor genes involved in DNA mismatch repair (MMR) have a distinct carcinogenic mechanism in ovarian tumors. DNA MMR is an endogenous molecular mechanism that reverses replication errors that escape correcting by replicative DNA polymerases. In MMR-defective cells, both base-to-base mismatches and insertion/deletion loops, are left uncorrected (40). This results in increased spontaneous somatic mutations. This effect is particularly obvious in non-expressed sequences comprising multiple simple repeats (microsatellites), and the characteristic microsatellite instability (MSI) is diagnostic for MMR-defective tumors $(41,42)$. Approximately $10 \%$ of ovarian cancers are related to this molecular pathway (43). Defective MMR is often a consequence of germ-line mutations in the $h M L H 1, h M S H 2, M G M T$ or, occasionally, MSH6 or PMS2 genes. Hypermethylation of the $M L H 1$ gene accompanied by loss of the gene expression has been reported in $10-30 \%$ of ovarian malignancies, while in cases with acquired resistance to platinum-based chemotherapy, $h M L H 1$ promoter methylation has been identified in $56 \%$ of cases $(44,45)$. The methylation frequency of $h M S H 2$ promoters has been reported to be as high as $57 \%$ in ovarian cancers. Methylation of hMSH2 correlated with histological grade and lymphatic metastasis. Additionally, the methylation rates of hMSH2 were significantly higher in endometrioid adenocarcinoma tissues compared to other pathological types of the disease (44).

RAS association domain family protein 1a (RASSF1A) which is an inhibitor of the anaphase-promoting complex, together with $O P C M L$, are among the most frequently methylated genes in ovarian cancer $(46,47)$. Genes involved in cell cycle pathways such as p16 and p15 have also been affected by altered methylation of their promoters (48). E-cadherin is a transmembrane glycoprotein that mediates calcium-dependent interactions between adjacent epithelial cells. It has been found that the risk of E-cadherin hypermethylation was 1.347-fold among patients with ovarian cancer than that among patients with benign ovarian lesions (48). Other genes involved in cell adherence, such as $\mathrm{H}$-cadherin and $\mathrm{CDH} 1$, have shown similar results (49). HSulf-1, which encodes an arylsulfatase that acts on cell surface heparin sulfate proteoglycans and inhibits growth factor signalling, was found to be methylated in $>50 \%$ of ovarian tumors and cell lines (50).

Methylation profiles of several genes belonging in the family of the Homeobox (HOX) genes have also been investigated in cases of ovarian carcinomas. Homeobox genes constitute a family of transcription factors that function during embryonic development to control pattern formation, differentiation, and proliferation (51). HOX genes are expressed in normal adult reproductive tissue where they are involved in regulating differentiation. Findings of previous studies suggest that the abnormal expression of particular $H O X$ genes is associated with ovarian cancers (52). Methylation of the HOXA9 gene has been observed in $95 \%$ of patients with high grade serous ovarian carcinoma (53). It has been suggested that the methylation status of HOXA9 and HOXAD11 genes may serve as potential diagnostic and prognostic biomarkers $(53,54)$.

The majority of studies assessing the methylation status of TSGs have focused on single genes with varying reported frequencies in different tissues. Hypermethylation in ovarian cancer, however, has been found to be associated with the inactivation of almost every pathway involved in ovarian cancer development, including DNA repair, cell cycle regulation, apoptosis, cell adherence and detoxification pathways (32,38,55-58).

In addition to the hypermethylation of promoter-associated $\mathrm{CpG}$ islands, global hypomethylation and specific hypomethylation of protein expressed genes that subsequently become overexpressed plays a significant role in ovarian cancer. Hypomethylation in the centromere and subtelomeric regions is involved in the induction of genomic instability (GI), leading to chromosomal translocations and gene disruption through the reactivation of transposable elements (21). Decreased methylation of LINE-1 elements is correlated with high grade, advanced stage and poor prognosis in ovarian cancer patients (59). Satellite DNA hypomethylation is an independent marker of poor prognosis. Hypomethylation is increased from non-neoplastic tissue toward ovarian cancer as well as advanced grade and stage (60).

In addition to repetitive elements and DNA satellites, a number of protein-coding genes are overexpressed in ovarian 
cancer, in association with promoter hypomethylation. Several oncogenes have been reported to have an increased epigenetically induced expression. Oncogenes such as CLDN4 (encoding an integral component of tight junctions), $M A L$ (mal, T-cell differentiation protein) and BORIS (brother of the regulator of imprinted sites) belong to a number of oncogenes that contribute to drug resistance and are associated with overall prognosis of the disease (61-63). Upregulation, together with hypomethylation of the ABCG2 multidrug transporter and $T U B B 3$ genes, which is a determinant of taxane resistance, have been observed in cases of advanced ovarian carcinoma with drug-acquired chemoresistance $(64,65)$. Other cancer-associated genes including MCJ $(66,67)$ and $S N G G$ (synucelin- $\gamma$ ), encoding an activator of the MAPK and Elk-1 signaling cascades $(63,68)$, are upregulated in ovarian cancer in association with DNA hypomethylation.

\section{Diagnosis}

Since aberrant methylation is one of the earliest molecular alterations during tumorigenesis, it has been suggested as a promising strategy for the early detection of ovarian cancer. However, methylation of single genes may have limited value in clinical applications. At present, no single epigenetic biomarker is able to accurately detect early ovarian cancer in either tissue or body fluids. Analysis of the methylation status of multiple genes simultaneously in a blood-based assay may provide a more sensitive and specific method for the molecular classification and prognosis of ovarian cancer.

A genome-wide DNAm profiling of a large ovarian cancer case control cohort demonstrated that active ovarian cancer has a significant impact on the DNAm pattern in peripheral blood (69). A microarray-based analysis on ovarian tumors identified 112 methylated loci prognostic for progression-free survival in advanced ovarian cancer patients (70). The data suggested that a higher degree of $\mathrm{CpG}$ island methylation is associated with early disease recurrence following chemotherapy (71). Promoter hypermethylation of at least one of six genes (BRCA1, RASSF1A, APC, p14ARF, p16INK4A and $D A P K$ ) was observed in $41 / 50$ ovarian cancer serum specimens. Thus, hypermethylation of certain genes may present an early event in ovarian tumorigenesis that can be detected in the serum DNA from patients with ovary-confined (stage IA or B) tumors and in cytologically negative peritoneal fluid (56). A recent study that used multiplex methylationspecific PCR to analyze the methylation status of cell-free serum DNA of seven candidate genes (APC, RASSF1A, CDH1, RUNX3, TFPI2, SFRP5 and OPCML), achieved a sensitivity and specificity of 85.3 and $90.5 \%$, respectively, in stage I OEC. The detection rates were markedly higher compared with a single CA125, which produced a sensitivity of $56.1 \%$ at $64.15 \%$ specificity (72). Another study demonstrated notable detection sensitivities and specificities using a 10-gene panel in plasma (73).

The role of DNA methylation biomarkers in ovarian cancer is promising. However, progression towards clinical practice is hampered by the lack of detection techniques combining high accuracy with low cost. The main obstacles that are to be overcome are the standardization of analysis techniques and establishment of reliable reference values.

\section{Treatment}

Chemoresistance. The current chemotherapy strategy in treating ovarian cancer patients involves a combination of a platinum- and a taxane-based therapy. While most ovarian cancer patients respond completely to chemotherapy, the majority of the initial responders eventually develop chemoresistance (74). In addition to mutations, DNA methylation-induced silencing of various drug response genes and pathways also facilitates the development of ovarian tumor cell drug resistance (75). It was shown that the silencing of SFRP5, which is a Wnt antagonist, by DNA hypermethylation was associated with platinum resistance of ovarian cancer (76). Similarly, hypermethylation of several genes such as $h M L H 1$, the arginine biosynthesisrelated gene ASS1, and ESR2 (encoding the ER-b) are involved in platinum resistance (77-79). Platinum resistance has also been correlated with stage-progressive hypermethylation of the Methylation Controlled DNAJ (MCJ) gene which resulted in loss of gene expression and correlated with a poor response to chemotherapy (67). DAPK, which is a gene involved in apoptosis, has also been shown to be silenced in drug-resistant cancer due to methylation (80).

In addition to the loss of expression due to DNA methylation, it was shown that hypomethylation along with an increase in expression of the myelin and lymphocyte protein $(M A L)$ gene is associated with platinum resistance (62). Hypomethylation and upregulation of the $A B C G 2$ multidrug transporter gene was also shown to occur during chemoresistance in two ovarian carcinoma cell lines (81). Based on the association of DNA methylation of specific genes with platinum sensitivity, it was shown that the hypomethylation-mediated activation of the cell growth-promoting pathways, PI3K/Akt, TGF- $\beta$ and cell cycle progression, may contribute to cisplatin resistance in ovarian cancer cells (82).

At present, only two biomarkers of protein origin (CA125 and HE4) are considered as indicators of response to chemotherapy. Epigenetic markers may supplement these proteins possibly by increasing their sensitivity and specificity. DNA methylation biomarkers in particular, have several advantages over other biomarkers such as proteins, gene expression and DNA mutations, since they are stable, can easily be distinguished, and can be detected in specific DNA regions $(\mathrm{CpG}$ islands) (83). In the future, the overall DNA methylation profile of the resected ovarian tumor may may be used for the development of individually tailored treatment regimens (84).

Epigenetic therapy. Unlike cancer-associated gene mutations, DNA methylation and other epigenetic modifications are potentially reversible. This makes epigenetic agents attractive candidates for disease prevention and resensitization to chemotherapeutic agents. Demethylation of tumor suppressor genes may have a positive effect in cancer progression, whereas the decrease of methylation of oncogenes which reactivate these genes, may have an adverse effect. There are two types of DNA methylation inhibitors: nucleoside and non-nucleoside analogues. Nucleoside analogues inhibit methylation when they are integrated into DNA and block the release of DNMTs by forming a covalent complex with these enzymes (85). They have been found to have clinical activities especially on hematopoietic malignancies (86-88). These inhibitors have been 
used to induce the re-expression of silenced TSGs caused by hypermethylation. Although aberrant promoter methylation is corrected by DNA methylation inhibitors, when the drug is stopped, the aberrant methylation and gene silencing is re-established (16). Non-nucleoside analogues are thus small molecular inhibitors that bind to the catalytic region of DNMTs and suppress translation.

Azacytidine and decitabine are the first two DNMT inhibitors approved for the therapy of myelodysplastic syndromes $(13,31)$. Decitabine, a potent methylation inhibitor, has been shown to cause demethylation in numerous ovarian cell lines, reversing the silencing of several TSGs $(89,90)$. Decitabine has also been reported to decrease cisplatin resistance in both ovarian cancer cells and a mouse xenograft through demethylation of the $h M L H 1$ promoter (91). Two clinical trials have provided evidence that azacytidine and decitabine are capable of reversing platinum resistance in ovarian cancer patients $(92,93)$. However, DNMT inhibitors may simultaneously cause widespread genomic hypomethylation that potentially leads to genomic instability (94).

Histone deacetylation is a well-known epigenetic mechanism that also contributes to silencing of TSGs in cancer. While HDACIs and DNMTIs have demonstrated clinical activity as single-agent therapies for hematopoietic malignancies, DNA methylation and histone deacetylation often co-ordinately inhibit gene transcription, and restoration of the two silencing mechanisms may be necessary for maximal gene derepression (13). Treatment with a DNMTI/HDACI combination, in ovarian cancer cases, was synergistic for upregulation of the pro-apoptotic gene TMSI/ASC, in contrast to either agent alone (95). An earlier integrated microarray analysis demonstrated that a DNMTI/HDACI-combined treatment of ovarian cancer cells affects more genes that either agent individually (96). Conventional chemotherapy together with methylation inhibitors have also been examined in phase I/II clinical trials. Decitabine in combination with carboplatin demonstrated no significant improvement over platinum alone in an ovarian cancer study (97). Another similar study that uses low-dose decitabine plus carboplatin resulted in more disease responses and established in vivo biological activity in blood and tumor specimens of ovarian cancer patients (93). Carboplatin when combined with 5-azacytidine also showed encouraging results (92).

\section{Conclusion}

Epigenetic alterations such as DNA methylation are clearly involved in ovarian cancer initiation and progression. Global DNA hypomethylation and localized hypermethylation of specific gene promoters contribute to genome instability and transcriptional silencing of tumor suppressor genes, respectively. Early studies focused on the methylation patterns of single genes associated with tumorigenesis. However, newer genome-wide methods have identified a group of genes whose regulation is altered by DNA methylation during ovarian cancer progression. The profiling of DNA methylomes may provide new insight into the development of biomarkers with clinical value for cancer risk assessment, early detection, prevention and prognosis. Therapeutic agents that target methylation are already being tested for future use and have proven beneficial in other types of malignancies. This is an exciting and rapidly evolving area of research in which investigations may lead to the possible detection of interindividual drug response differences and their reversal.

\section{References}

1. Hennessy BT, Coleman RL and Markman M: Ovarian cancer. Lancet 374: 1371-1382, 2009.

2. Jemal A, Siegel R, Ward E, Hao Y, Xu J and Thun MJ: Cancer statistics, 2009. CA Cancer J Clin 59: 225-249, 2009.

3. Bookman MA, Brady MF, McGuire WP, et al: Evaluation of new platinum-based treatment regimens in advanced-stage ovarian cancer: a Phase III Trial of the Gynecologic Cancer Intergroup. J Clin Oncol 27: 1419-1425, 2009.

4. Claus EB, Schildkraut JM, Thompson WD and Risch NJ: The genetic attributable risk of breast and ovarian cancer. Cancer 77: 2318-2324, 1996.

5. Antoniou A, Pharoah PD, Narod S, et al: Average risks of breast and ovarian cancer associated with BRCA1 or BRCA 2 mutations detected in case Series unselected for family history: a combined analysis of 22 studies. Am J Hum Genet 72: 1117-1130, 2003.

6. Tian C, Ambrosone CB, Darcy KM, Krivak TC, Armstrong DK, Bookman MA, Davis W, Zhao H, Moysich K, Gallion $\mathrm{H}$ and DeLoia JA: Common variants in ABCB1, ABCC2 and ABCG2 genes and clinical outcomes among women with advanced stage ovarian cancer treated with platinum and taxane-based chemotherapy: a Gynecologic Oncology Group study. Gynecol Oncol 124: 575-581, 2012.

7. Darcy KM, Brady WE, Blancato JK, Dickson RB, Hoskins WJ, McGuire WP and Birrer MJ: Prognostic relevance of c-MYC gene amplification and polysomy for chromosome 8 in suboptimally-resected, advanced stage epithelial ovarian cancers: a Gynecologic Oncology Group study. Gynecol Oncol 114: 472-479, 2009.

8. Tuefferd M, Couturier J, Penault-Llorca F, Vincent-Salomon A, Broët P, Guastalla JP, Allouache D, Combe M, Weber B, PujadeLauraine E and Camilleri-Broët S: HER2 status in ovarian carcinomas: a multicenter GINECO study of 320 patients. PLoS One 2: e1138, 2007

9. Baylin SB and Ohm JE: Epigenetic gene silencing in cancera mechanism for early oncogenic pathway addiction? Nat Rev Cancer 6: 107-116, 2006.

10. Ushijima T and Asada K: Aberrant DNA methylation in contrast with mutations. Cancer Sci 101: 300-305, 2010.

11. Yoo CB and Jones PA: Epigenetic therapy of cancer: past, present and future. Nat Rev Drug Discov 5: 37-50, 2006.

12. Russo VEA, Riggs AD and Martienssen RA: Epigenetic mechanisms of gene regulation. Cold Spring Harbor Laboratory Press, Plainview, NY, 1996.

13. Jones PA and Baylin SB: The epigenomics of cancer. Cell 128: 683-692, 2007.

14. Wilting RH and Dannenberg JH: Epigenetic mechanisms in tumorigenesis, tumor cell heterogeneity and drug resistance. Drug Resist Updat 15: 21-38, 2012.

15. Koukoura O, Sifakis $\mathrm{S}$ and Spandidos DA: DNA methylation in the human placenta and fetal growth (Review). Mol Med Rep 5: 883-839, 2012.

16. Herman JG and Baylin SB: Gene silencing in cancer in association with promoter hypermethylation. N Engl J Med 349: 2042-2054, 2003.

17. Weber M and Schubeler D: Genomic patterns of DNA methylation: targets and function of an epigenetic mark. Curr Opin Cell Biol 19: 273-280, 2007.

18. Bird AP and Wolffe AP: Methylation-induced repression - belts, braces, and chromatin. Cell 99: 451-454, 1999.

19. Costello JF and Plass C: Methylation matters. J Med Genet 38: 285-303, 2001

20. Catteau A, Harris WH, Xu CF and Solomon E: Methylation of the BRCA1 promoter region in sporadic breast and ovarian cancer: correlation with disease characteristics. Oncogene 18: 1957-1965, 1999

21. Esteller M: Epigenetics in cancer. N Engl J Med 358: 1148-1159, 2008.

22. Esteller M, Silva JM, Dominguez G, et al: Promoter hypermethylation and BRCA1 inactivation in sporadic breast and ovarian tumors. J Natl Cancer Inst 92: 564-569, 2000. 
23. Baylin SB and Chen WY: Aberrant gene silencing in tumor progression: implications for control of cancer. Cold Spring Harb Symp Quant Biol 70: 427-433, 2005.

24. Horak P, Pils D, Haller G, et al: Contribution of epigenetic silencing of tumor necrosis factor-related apoptosis inducing ligand receptor 1 (DR4) to TRAIL resistance and ovarian cancer. Mol Cancer Res 3: 335-343, 2005.

25. Petrocca F, Iliopoulos D, Qin HR, et al: Alterations of the tumor suppressor gene ARLTS1 in ovarian cancer. Cancer Res 66: 10287-10291, 2006.

26. Yu Y, Fujii S, Yuan J, et al: Epigenetic regulation of ARHI in breast and ovarian cancer cells. Ann NY Acad Sci 983: 268-277, 2003.

27. Baldwin RL, Nemeth E, Tran $\mathrm{H}$, et al: BRCA1 promoter region hypermethylation in ovarian carcinoma: a population-based study. Cancer Res 60: 5329-5333, 2000.

28. Hilton JL, Geisler JP, Rathe JA, Hattermann-Zogg MA, DeYoung B and Buller RE: Inactivation of BRCA1 and BRCA2 in ovarian cancer. J Natl Cancer Inst 94: 1396-1406, 2002.

29. Li ML and Greenberg RA: Links between genome integrity and BRCA1 tumor suppression. Trends Biochem Sci 37: 418-424, 2012

30. McCoy ML, Mueller CR and Roskelley CD: The role of the breast cancer susceptibility gene 1 (BRCA1) in sporadic epithelial ovarian cancer. Reprod Biol Endocrinol 1: 72, 2003.

31. Rzepecka IK, Szafron L, Stys A, et al: High frequency of allelic loss at the BRCA1 locus in ovarian cancers: clinicopathologic and molecular associations. Cancer Genet 205: 94-100, 2012.

32. Strathdee G, Appleton K, Illand M, et al: Primary ovarian carcinomas display multiple methylator phenotypes involving known tumor suppressor genes. Am J Pathol 158: 1121-1127, 2001.

33. Chan KY, Ozcelik H, Cheung AN, Ngan HY and Khoo US: Epigenetic factors controlling the BRCA1 and BRCA2 genes in sporadic ovarian cancer. Cancer Res 62: 4151-4156, 2002.

34. Wang YQ, Yan Q, Zhang JR, Li SD, Yang YX and Wan XP Epigenetic inactivation of BRCA1 through promoter hypermethylation in ovarian cancer progression. J Obstet Gynaecol Res 39: 549-554, 2013.

35. Wang C, Horiuchi A, Imai T, et al: Expression of BRCA1 protein in benign, borderline, and malignant epithelial ovarian neoplasms and its relationship to methylation and allelic loss of the BRCA1 gene. J Pathol 202: 215-223, 2004.

36. Yang HJ, Liu VW, Wang Y, Tsang PC and Ngan HY: Differential DNA methylation profiles in gynecological cancers and correlation with clinico-pathological data. BMC Cancer 6: 212, 2006

37. Bol GM, Suijkerbuijk KP, Bart J, Vooijs M, van der Wall E and van Diest PJ: Methylation profiles of hereditary and sporadic ovarian cancer. Histopathology 57: 363-370, 2010.

38. Rathi A, Virmani AK, Schorge JO, et al: Methylation profiles of sporadic ovarian tumors and nonmalignant ovaries from high-risk women. Clin Cancer Res 8: 3324-3331, 2002.

39. Kontorovich T, Cohen Y, Nir U and Friedman E: Promoter methylation patterns of ATM, ATR, BRCA1, BRCA2 and p53 as putative cancer risk modifiers in Jewish BRCA1/BRCA2 mutation carriers. Breast Cancer Res Treat 116: 195-200, 2009.

40. Blasi MF, Ventura I, Aquilina G, et al: A human cell-based assay to evaluate the effects of alterations in the MLH1 mismatch repair gene. Cancer Res 66: 9036-9044, 2006.

41. Jiricny $\mathrm{J}$ and Nyström-Lahti M: Mismatch repair defects in cancer. Curr Opin Genet Dev 10: 157-161, 2000

42. Kunkel TA and Erie DA: DNA mismatch repair. Annu Rev Biochem 74: 681-710, 2005.

43. Murphy MA and Wentzensen N: Frequency of mismatch repair deficiency in ovarian cancer: a systematic review. This article is a US Government work and, as such, is in the public domain of the United States of America. Int J Cancer 129: 1914-1922, 2011.

44. Zhang H, Zhang S, Cui J, Zhang A, Shen L and Yu H: Expression and promoter methylation status of mismatch repair gene hMLH1 and hMSH2 in epithelial ovarian cancer. Aust N Z J Obstet Gynaecol 48: 505-509, 2008.

45. Watanabe Y, Ueda H, Etoh T, et al: A change in promoter methylation of hMLH1 is a cause of acquired resistance to platinum-based chemotherapy in epithelial ovarian cancer. Anticancer Res 27: 1449-1452, 2007.

46. Barton CA, Hacker NF, Clark SJ and O'Brien PM: DNA methylation changes in ovarian cancer: implications for early diagnosis, prognosis and treatment. Gynecol Oncol 109: 129-139, 2008.

47. Ozdemir F, Altinisik J, Karateke A, Coksuer H and Buyru N Methylation of tumor suppressor genes in ovarian cancer. Exp Ther Med 4: 1092-1096, 2012 .
48. Moselhy SS, Kumosani TA, Kamal IH, Jalal JA, Abdul Jabaar HS and Dalol A: Hypermethylation of P15, P16, and E-cadherin genes in ovarian cancer. Toxicol Ind Health: Apr 9, 2013 (Epub ahead of print)

49. Dhillon VS, Young AR, Husain SA and Aslam M: Promoter hypermethylation of MGMT, CDH1, RAR-beta and SYK tumour suppressor genes in granulosa cell tumours (GCTs) of ovarian origin. Br J Cancer 90: 874-881, 2004.

50. Staub J, Chien J, Pan Y, et al: Epigenetic silencing of HSulf-1 in ovarian cancer: implications in chemoresistance. Oncogene 26: 4969-4978, 2007.

51. Samuel S and Naora H: Homeobox gene expression in cancer: insights from developmental regulation and deregulation. Eur J Cancer 41: 2428-2437, 2005.

52. Kelly ZL, Michael A, Butler-Manuel S, Pandha HS and Morgan RG: HOX genes in ovarian cancer. J Ovarian Res 4: 16, 2011.

53. Montavon C, Gloss BS, Warton K, et al: Prognostic and diagnostic significance of DNA methylation patterns in high grade serous ovarian cancer. Gynecol Oncol 124: 582-588, 2012

54. Widschwendter M, Apostolidou S, Jones AA, et al: HOXA methylation in normal endometrium from premenopausal women is associated with the presence of ovarian cancer: a proof of principle study. Int J Cancer 125: 2214-2218, 2009.

55. Swisher EM, Gonzalez RM, Taniguchi T, et al: Methylation and protein expression of DNA repair genes: association with chemotherapy exposure and survival in sporadic ovarian and peritoneal carcinomas. Mol Cancer 8: 48, 2009.

56. Ibanez de Caceres I, Battagli C, Esteller M, et al: Tumor cellspecific BRCA1 and RASSF1A hypermethylation in serum, plasma, and peritoneal fluid from ovarian cancer patients. Cancer Res 64: 6476-6481, 2004

57. Makarla PB, Saboorian MH, Ashfaq R, et al: Promoter hypermethylation profile of ovarian epithelial neoplasms. Clin Cancer Res 11: 5365-5369, 2005.

58. Tam KF, Liu VW, Liu SS, et al: Methylation profile in benign, borderline and malignant ovarian tumors. J Cancer Res Clin Oncol 133: 331-341, 2007.

59. Pattamadilok J, Huapai N, Rattanatanyong P, et al: LINE-1 hypomethylation level as a potential prognostic factor for epithelial ovarian cancer. Int J Gynecol Cancer 18: 711-717, 2008.

60. Widschwendter M, Jiang G, Woods C, et al: DNA hypomethylation and ovarian cancer biology. Cancer Res 64: 4472-4480, 2004.

61. Honda H, Pazin MJ, Ji H, Wernyj RP and Morin PJ: Crucial roles of Sp1 and epigenetic modifications in the regulation of the CLDN4 promoter in ovarian cancer cells. J Biol Chem 281: 21433-21444, 2006.

62. Lee PS, Teaberry VS, Bland AE, et al: Elevated MAL expression is accompanied by promoter hypomethylation and platinum resistance in epithelial ovarian cancer. Int J Cancer 126: 1378-1389, 2010.

63. Woloszynska-Read A, James SR, Link PA, Yu J, Odunsi K and Karpf AR: DNA methylation-dependent regulation of BORIS/ CTCFL expression in ovarian cancer. Cancer Immun 7: 21, 2007.

64. Izutsu N, Maesawa C, Shibazaki M, et al: Epigenetic modification is involved in aberrant expression of class III $\beta$-tubulin, TUBB3, in ovarian cancer cells. Int J Oncol 32: 1227-1235, 2008.

65. Balch C, Matei DE, Huang TH and Nephew KP: Role of epigenomics in ovarian and endometrial cancers. Epigenomics 2 : 419-447, 2010

66. Strathdee G, Davies BR, Vass JK, Siddiqui N and Brown R: Cell type-specific methylation of an intronic $\mathrm{CpG}$ island controls expression of the MCJ gene. Carcinogenesis 25: 693-701, 2004.

67. Strathdee G, Vass JK, Oien KA, Siddiqui N, Curto-Garcia J and Brown R: Demethylation of the MCJ gene in stage III/IV epithelial ovarian cancer and response to chemotherapy. Gynecol Oncol 97: 898-903, 2005

68. Gupta A, Godwin AK, Vanderveer L, Lu A and Liu J: Hypomethylation of the synuclein gamma gene $\mathrm{CpG}$ island promotes its aberrant expression in breast carcinoma and ovarian carcinoma. Cancer Res 63: 664-673, 2003.

69. Teschendorff AE, Menon U, Gentry-Maharaj A, et al: An epigenetic signature in peripheral blood predicts active ovarian cancer. PLoS One 4: e8274, 2009.

70. Wei SH, Balch C, Paik HH, et al: Prognostic DNA methylation biomarkers in ovarian cancer. Clin Cancer Res 12: 2788-2794, 2006. 
71. Wei SH, Chen CM, Strathdee G, et al: Methylation microarray analysis of late-stage ovarian carcinomas distinguishes progression-free survival in patients and identifies candidate epigenetic markers. Clin Cancer Res 8: 2246-2252, 2002.

72. Zhang Q, Hu G, Yang Q, et al: A multiplex methylation-specific PCR assay for the detection of early-stage ovarian cancer using cell-free serum DNA. Gynecol Oncol 130: 132-139, 2013.

73. Melnikov A, Zaborina O, Dhiman N, Prabhakar BS Chakrabarty AM and Hendrickson W: Clinical and environmental isolates of Burkholderia cepacia exhibit differential cytotoxicity towards macrophages and mast cells. Mol Microbiol 36: 1481-1493, 2000.

74. Ozols RF: Systemic therapy for ovarian cancer: current status and new treatments. Semin Oncol 33: S3-S11, 2006.

75. Balch C, Huang TH, Brown R and Nephew KP: The epigenetics of ovarian cancer drug resistance and resensitization. Am J Obstet Gynecol 191: 1552-1572, 2004.

76. Su HY, Lai HC, Lin YW, et al: Epigenetic silencing of SFRP5 is related to malignant phenotype and chemoresistance of ovarian cancer through Wnt signaling pathway. Int J Cancer 127: 555-567, 2010.

77. Nicholson LJ, Smith PR, Hiller L, et al: Epigenetic silencing of argininosuccinate synthetase confers resistance to platinuminduced cell death but collateral sensitivity to arginine auxotrophy in ovarian cancer. Int J Cancer 125: 1454-1463, 2009.

78. Strathdee G, MacKean MJ, Illand M and Brown R: A role for methylation of the hMLH1 promoter in loss of hMLH1 expression and drug resistance in ovarian cancer. Oncogene 18 : 2335-2341, 1999

79. Yap OW, Bhat G, Liu L and Tollefsbol TO: Epigenetic modifications of the estrogen receptor beta gene in epithelial ovarian cancer cells. Anticancer Res 29: 139-144, 2009.

80. Lehmann U, Celikkaya G, Hasemeier B, Langer F and Kreipe H: Promoter hypermethylation of the death-associated protein kinase gene in breast cancer is associated with the invasive lobular subtype. Cancer Res 62: 6634-6638, 2002.

81. Curley MD, Therrien VA, Cummings CL, et al: CD133 expression defines a tumor initiating cell population in primary human ovarian cancer. Stem Cells 27: 2875-2883, 2009.

82. Li M, Balch C, Montgomery JS, et al: Integrated analysis of DNA methylation and gene expression reveals specific signaling pathways associated with platinum resistance in ovarian cancer. BMC Med Genomics 2: 34, 2009.

83. Laird PW: The power and the promise of DNA methylation markers. Nat Rev Cancer 3: 253-266, 2003.

84. Ivanov M, Kacevska M and Ingelman-Sundberg M: Epigenomics and interindividual differences in drug response. Clin Pharmacol Ther 92: 727-736, 2012.
85. Santi DV, Norment A and Garrett CE: Covalent bond formation between a DNA-cytosine methyltransferase and DNA containing 5-azacytosine. Proc Natl Acad Sci USA 81: 6993-6997, 1984.

86. Kaminskas E, Farrell A, Abraham S, et al: Approval summary: azacitidine for treatment of myelodysplastic syndrome subtypes. Clin Cancer Res 11: 3604-3608, 2005.

87. Issa JP, Garcia-Manero G, Giles FJ, et al: Phase 1 study of low-dose prolonged exposure schedules of the hypomethylating agent 5-aza-2'-deoxycytidine (decitabine) in hematopoietic malignancies. Blood 103: 1635-1640, 2004.

88. Issa JP, Gharibyan V, Cortes J, et al: Phase II study of low-dose decitabine in patients with chronic myelogenous leukemia resistant to imatinib mesylate. J Clin Oncol 23: 3948-3956, 2005.

89. Sasaki M, Kaneuchi M, Fujimoto S, Tanaka Y and Dahiya R: Hypermethylation can selectively silence multiple promoters of steroid receptors in cancers. Mol Cell Endocrinol 202: 201-207, 2003.

90. Takai N, Kawamata N, Walsh CS, et al: Discovery of epigenetically masked tumor suppressor genes in endometrial cancer. Mol Cancer Res 3: 261-269, 2005.

91. Plumb JA, Strathdee G, Sludden J, Kaye SB and Brown R: Reversal of drug resistance in human tumor xenografts by 2'-deoxy-5-azacytidine-induced demethylation of the hMLH1 gene promoter. Cancer Res 60: 6039-6044, 2000.

92. Fu S, Hu W, Iyer R, et al: Phase 1b-2a study to reverse platinum resistance through use of a hypomethylating agent, azacitidine, in patients with platinum-resistant or platinum-refractory epithelial ovarian cancer. Cancer 117: 1661-1669, 2011.

93. Fang F, Balch C, Schilder J, et al: A phase 1 and pharmacodynamic study of decitabine in combination with carboplatin in patients with recurrent, platinum-resistant, epithelial ovarian cancer. Cancer 116: 4043-4053, 2010.

94. Chen H, Hardy TM and Tollefsbol TO: Epigenomics of ovarian cancer and its chemoprevention. Front Genet 2: 67, 2011.

95. Terasawa K, Sagae S, Toyota M, et al: Epigenetic inactivation of TMS1/ASC in ovarian cancer. Clin Cancer Res 10: 2000-2006, 2004.

96. Shi H, Wei SH, Leu YW, et al: Triple analysis of the cancer epigenome: an integrated microarray system for assessing gene expression, DNA methylation, and histone acetylation. Cancer Res 63: 2164-2171, 2003.

97. Appleton K, Mackay HJ, Judson I, et al: Phase I and pharmacodynamic trial of the DNA methyltransferase inhibitor decitabine and carboplatin in solid tumors. J Clin Oncol 25: 4603-4609, 2007. 